\title{
A QUESTÃO DO DESENVOLVIMENTO E OS DESDOBRAMENTOS RECENTES DO PROCESSO DE FRAGMENTAÇÃO DO ESPAÇO URBANO EM RECIFE/PE - O CASO DO "PROJETO NOVO RECIFE"
}

\author{
THE QUESTION OF DEVELOPMENT AND THE RECENT EVENTS \\ OF THE FRAGMENTATION PROCESS OF URBAN SPACE IN \\ RECIFE / PE - THE CASE OF "PROJETO NOVO RECIFE" \\ LA CUESTIÓN DE DESARROLLO Y LOS DESDOBLAMIENTOS \\ RECIENTES DEL PROCESO DE FRAGMENTACIÓN DEL ESPACIO \\ URBANO EN RECIFE/PE - EL CASO DEL "PROJETO NOVO RECIFE”
}

Otávio Augusto Alves dos Santos - Universidade Federal de Pernambuco - Recife - Pernambuco - Brasil

otavioaas@gmail.com

Edvânia Tôrres Aguiar Gomes- Universidade Federal de Pernambuco - Recife - Pernambuco - Brasil

torres@ufpe.br

Resumo

0 objetivo desse trabalho é analisar alguns dos desdobramentos mais significativos do processo crescente de "fragmentação do espaço" urbano em Recife, resultante do modelo de desenvolvimento adotado e orientado segundo uma "lógica vertical" de reprodução capitalista do espaço. Para isso, busca-se compreender a relação entre desenvolvimento e "fragmentação do espaço" urbano, bem como 0 caráter das práticas de planejamento e gestão urbanos, numa cidade à deriva das estratégias privatizantes do capital imobiliário. 0 s argumentos reflexivos têm por base uma breve incursão histórica e uma análise concisa do Projeto Novo Recife/PE, um dos principais mega-empreendimentos hoje em evidência nessa cidade.

Palavras-chave: desenvolvimento, fragmentação, projeto Novo Recife.

\section{Abstract}

The purpose of this work is to point out some of the most significant elements of the growing process of fragmentation of the urban space in the city of Recife. This process occurs as a result of the developing model adopted and oriented by a "vertical logic" of capitalist production of space. Therefore, we seek to understand the relationship between development and fragmentation of the urban space, as well as the character of urban planning and management practices in a city adrift of privatizing strategies of real estate capital. The reflective arguments are based on a brief historical incursion and a concise analysis of the Projeto Novo Recife/PE, one of the mega-projects in evidence in the city today.

Keywords: development, fragmentation, projeto Novo Recife.

\section{Resumen}

El objetivo de este trabajo es analizar algunos de los desdoblamientos más significativos del creciente proceso de "fragmentación del espacio" urbano en Recife, producto del modelo de desarrollo adoptado y orientado según una "lógica vertical" de reproducción capitalista. Para ello, se busca comprender la relación entre el desarrollo y la "fragmentación del espacio" urbano así como el carácter de las prácticas de planeación y gestión urbana en una ciudad al borde de las estrategias de privatización del capital inmobiliario, a través de 
una breve incursión histórica. Los argumentos reflexivos toman como base una breve incursión histórica y un análisis conciso del "Projeto Novo Recife/ PE", uno de los principales mega-emprendimientos, actualmente en evidencia, en esa ciudad.

Palabras-clave: desarrollo, fragmentación, proyecto Novo Recife.

\section{Introdução}

O desenvolvimento, elevado à categoria de axioma do capitalismo industrial, pressupõe a adesão irrestrita e hegemônica da globalização, no âmbito da qual se mobilizam esforços de diferentes escalas e intensidades, na busca de sua realização mais-que-perfeita. Idealmente concebido enquanto crescente melhoria das condições de reprodução da vida humana, os resultados concretos do desenvolvimento capitalista guardam as suas contradições. Para muitos, contradições que soam paradoxais, sobretudo quando se considera a experiência dos países da periferia do sistema mundial.

Para a grande maioria dos países periféricos, como o Brasil, a adesão ao extraordinário mundo globalizado dos progressos técnico-científicos quase sempre corresponde a um caminho seguro para mais desigualdades sociais e "fragmentação do espaço"1. Isto ocorre, vale dizer, porque os vetores da regulação hierárquica provenientes do desenvolvimento, as chamadas "verticalidades" (Santos, 1996), tendem a beneficiar os atores e lugares hegemônicos do sistema-mundo, transformando outros atores e lugares em simples assimiladores de produtos e técnicas, fadados a ocupar sempre o mesmo posto na divisão internacional do trabalho. Ao invés em deconstituir uma cidadania universal, argumenta Santos (2008), tais progressos técnico-científicos da globalização empobrecem e descaracterizam os lugares, uniformizando-os apenas no que diz respeito à tirania do dinheiro e da informação.

Com efeito, este tal axiomático "desenvolvimento" tem sido o principal instrumento à progressiva ampliação espacial dos mercados e da produção capitalistas, em um movimento que Harvey (2006) chamou de "geografia da acumulação capitalista". Não obstante, nesse movimento hegemônico de acumulação, quaisquer processos que contrastem são

\footnotetext{
${ }^{1}$ Referimo-nos às diferentes formas de apropriação do espaço para o trabalho e para o consumo que, como sugeriu Salgueiro (1998), indicam enclaves territoriais distintos e traduzem as rupturas entre os diferentes grupos sociais e organizações. Como bem lembra Carlos (1998), muitas dessas atuais formas de fragmentação têm sido ocasionadas pela própria constituição global da "sociedade urbana", tendo as desiguais metrópoles periféricas como exemplo mais eloqüente.
} 
definidos como "limites do desenvolvimento". Isso é particularmente evidente nas grandes cidades da periferia do capitalismo, onde o padrão colonial latino-americano de valorização forjou um espaço urbano extremamente fragmentado, muitas vezes solapando, sob a justificativa do pleno desenvolvimento, formas geográficas anteriores de lenta decantação social e natural. Hoje, a supracitada fragmentação do espaço tem sido reforçada pela irrupção de um conjunto de planos de intervenção urbana, cuja justificação mais uma vez reside no desenvolvimento e cuja materialização tem se dado na contravia de formas geográficas importantes à memória da cidade.

O "desenvolvimento", qual seja o processo de valorização do espaço orientado por uma "lógica vertical" e enredado segundo o movimento geograficamente expansível do Capital, tem por consequência objetiva a produção de um espaço essencialmente fragmentado. Não só porque o espaço das cidades, ao centralizar a maior parte da produção capitalista, tende a manifestar sua natureza socioespacialmente desigual de maneira mais nítida, mas também porque nele, mais do que em quaisquer outros espaços, a "ordem distante" tende a se sobrepor à "ordem próxima" (Lefebvre, 2001), diferentes tempos o fracionam e o recompõem, ordenando-o preferencialmente segundo os interesses das grandes firmas globais.

O objetivo desse trabalho é analisar alguns dos desdobramentos mais recentes dessa fragmentação do espaço em Recife, apresentando-a enquanto resultado de um modelo de desenvolvimento que beneficia o capital imobiliário, ao passo que relega aos trabalhadores seus problemas sociais e ambientais. Esse objetivo tem sido perseguido com base no estudo da trajetória do planejamento urbano na cidade do Recife durante o século $\mathrm{XX}$, bem como a partir de reflexões em torno de um dos principais megaempreendimentos hoje em evidência nessa cidade, o Projeto Novo Recife. O trabalho em tela é também resultado das reflexões e vivências que tem se dado no âmbito das pesquisas e leituras desenvolvidas nos Grupos de Pesquisas Nexus: Sociedade e Natureza, da Universidade Federal de Pernambuco. No primeiro item, procura-se demonstrar a íntima relação entre o desenvolvimento capitalista e o processo de fragmentação do espaço urbano. Posteriormente, questiona-se a contribuição do Estado e do planejamento urbano no referido processo. Por fim, discute-se o Projeto Novo Recife. 
Desenvolvimento e fragmentação do espaço urbano

A missão civilizatória do capital pela via do desenvolvimento pode ser também compreendida a partir da concepção de Moraes, Costa (1987) segunda a qual há um processo global de "valorização capitalista do espaço". Os autores afirmam que o regime de capital é capaz de mobilizar forças em diferentes lugares sob a forma de trabalho social, criando valor, ou seja, produtos materiais destinados a completar o ciclo de valorização do capital. Tais produtos agregam-se ao solo em forma de trabalho morto, constituindo, assim, um novo espaço sobre o qual novos processos de valorização irão incidir.

Considerando as transformações ocasionadas pelos sistemas técnicos, Milton Santos acrescenta que, em atenção a determinações e técnicas advindas de processos homogeneizantes, os espaços são constantemente dotados de "sistemas de engenharia", de objetos técnicos (formas) que se dispõem enquanto sistema e que são preenchidos e animados pela sociedade em movimento (conteúdos). Tais processos impõem-se sobre os lugares, desarranjando seus modos de produção, organizando-os segundo parâmetros estranhos ao lugar e afastando, por isso mesmo, a possibilidade de se restabelecer relações mais totalizantes do homem com seu ambiente (Santos, 1996).

Portanto, a valorização imposta pela lógica vertical - muitas vezes ao par de um processo de desvalorização e revalorização - quase sempre se destina à construção de formas espaciais indispensáveis aos ganhos econômicos das grandes firmas globais, à revelia das e, muitas vezes, em desacordo com as necessidades e interesses dos trabalhadores. Foi neste mesmo sentido, inclusive, que Santos e Silveira (2008) caracterizaram a modernização do território brasileiro. Impulsionada pelos imperativos do progresso e do desenvolvimento, a modernização do território deu-se por um processo de valorização capitalista que possibilitou, entre outras coisas, a operação racional das grandes firmas globais, muitas vezes constrangendo as iniciativas e os interesses nacionais.

As cidades brasileiras espelham exemplarmente as marcas desse modelo de desenvolvimento instaurado no país. Elas são o laboratório por meio do qual é possível constatar a materialidade dos mecanismos de imposição do modelo de urbanismo que se insere nesta perspectiva de "desenvolvimento". As cidades, na contemporaneidade, são resultados 
concretos da fluidez do território (Santos; Silveira, 2008), além de manifestarem espacialmente o processo global de constituição da sociedade urbana (Carlos, 1998).

Dado o próprio modelo de desenvolvimento desigual implantado no território, as cidades brasileiras apresentam hoje um espaço fortemente fragmentado. Da mesma forma em que desencadeou uma integração desigual no âmbito da qual vicejou a densidade e rapidez da famosa região concentrada, em nítido contraste com as áreas de rarefação e lentidão do interior do Norte e Nordeste (Santos; Silveira, 2008), esse modelo de desenvolvimento também ocasionou êxodo rural, inchaço populacional das grandes cidades e a permanência de uma pobreza urbana estrutural.

Grandes levas de trabalhadores desgarrados do campo e das péssimas condições de trabalho dirigiram-se às cidades durante a segunda metade do século XX sem, contudo, conseguir se inserir plenamente na economia urbana formal. Esses indivíduos sem trabalho e renda fixos, despojados de qualquer possibilidade de consumo pleno do espaço urbano, foram obrigados a lançar mão de mecanismos extremamente precários para garantir sua reprodução. Foi assim que insurgiu o "circuito inferior da economia" (Santos, 2004) e as grandes aglomerações do operariado urbano informal, cuja presença na cidade, segundo Davis (2006), caracteriza a urbanização no capitalismo periférico e o próprio ritmo da urbanização no mundo.

Fragmentadas, as metrópoles da periferia do capitalismo constituem lócus preferencial de manifestação das desigualdades sociais inerentes ao modelo de desenvolvimento capitalista, pois sustentam o paradoxo de condensar grandes quantidades de processos de valorização sem que seus habitantes as usufruam - exceto pela inserção nos mecanismos formalizados (ou não) de mercado². Além disso, a primazia de uma lógica vertical vigoriza a busca pela inserção na economia global e viabiliza transformações espaciais cuja função é garantir o lucro das grandes firmas

\footnotetext{
${ }^{2}$ Tais desigualdades ocorrem não apenas no que concerne à apropriação do valor, mas, também, na distribuição dos malgrados ambientais. Neste sentido, mesmo promovendo mudanças qualitativas as mais notáveis, o desenvolvimento que nunca foi democrático -, a o favorecer a classe dominante, quase sempre impôs às classes sociais subalternas a situação de ter que lidar com seus subprodutos ambientalmente negativos, precarizando-os duplamente. É neste sentido que, junto ao debate sobre o desenvolvimento, vem se consolidando as discussões sobre as chamadas "injustiças ambientais". Tal conceito, inclusive, surgiu nos marcos do debate sobre o crescimento econômico e a deposição de lixo nos bairros mais populares das cidades norte-americanas
} 
globais, muitas vezes em detrimento de formas espaciais essenciais à memória da cidade.

A cidade do Recife exemplifica a materialidade desse processo de fragmentação do espaço. Em função de uma incessante busca por modernização, iniciada ainda na primeira metade do século XX, o Recife e, consequentemente, a área metropolitana que a integra, acataram com quase nenhuma resistência a um intenso processo de valorização orquestrado pelo mercado imobiliário - com o generoso apoio do Estado e dos gestores urbanos, diga-se de passagem, - em um modelo de desenvolvimento que o fez possuir hoje um espaço extremamente fracionado, marcado pela presença de uma pobreza persistente, de profundos desequilíbrios ecológicos e agressões ao patrimônio histórico coletivo.

\section{Fragmentação do espaço e planejamento urbano em Recife}

Surgida a partir do porto natural e de fortalezas antes pertencente à cidade de Olinda, o núcleo a partir do qual se desenvolveu a cidade do Recife correspondia a uma pequena vila de moradores e comerciantes até o inicio do século XVII. O espaço natural sobre o qual esta cidade inicialmente se edificou consistia em uma região sedimentar flúviomarinha de onde desaguavam os rios Capibaribe e Beberibe, repleta de alagadiços e formações dos ecossistemas manguezal e restinga. $\mathrm{O}$ processo de valorização do espaço tem início quando da implantação das atividades econômicas coloniais, pois foi a partir desse momento que as terras conquistadas passaram a se integrar às atividades mercantis globais. A atividade canavieira foi a mais importante nesse período. A apropriação social da terra e o posterior uso econômico não-produtivo foi, entretanto, o principal fator de riquezas.

Em resumidas contas, a cidade do Recife se formou com base na conquista histórica dos melhores lugares (isto é, terras firmes e infraestruturadas) por parte dessa classe de proprietários, fazendo com que os trabalhadores em grande situação de precariedade não tivessem outra opção senão ocupar os piores lugares, geralmente os mais difíceis de serem devidamente habitados (alagadiços e encostas dos morros).

Em 1850, com a Lei de Terras e, sobretudo, a partir do início do século XX, quando do início da industrialização e do crescimento populacional, o mercado de terras na cidade veio a se acirrar. Assim, 
para a burguesia latifundiária urbana, o parcelamento e o mercado de terras sempre foram uma próspera e segura atividade econômica. Essa valorização do espaço pautada excepcionalmente pela conquista e mercado de terras não propiciou o desenvolvimento das forças produtivas, nem alavancou o patamar tecnológico, mas, paradoxalmente, seu caráter especulativo fez com que o acesso à cidade se tornasse, desde então, um privilégio de poucos.

Soma-se a isso o fato de que as áreas alagadiças e estuarinas, incorporadas à União enquanto "terrenos de marinha” desde 1831, foram também apropriadas pela burguesia latifundiária por meio do instituto do "aforamento". Com o apoio do Estado, tal classe conseguia expulsar os trabalhadores desses lugares no intuito de praticar aterros e fazer uso econômico dos terrenos. Isso, obviamente, ocasionou conflitos sociais de monta, sobretudo aqueles relacionados aos direitos de propriedade (Falcão Neto; Souza, 1985).

As respostas do poder público a tais conflitos quase sempre surgiram no sentido de atender aos interesses da burguesia. As ações do Estado nessa época limitavam-se a medidas discricionárias, embebidas de ideais higienistas e que recaiam implacavelmente sobre os trabalhadores. O urbanismo, diga-se de passagem, surgiu nesta cidade no âmbito do processo de reforma de seu centro, também pautado em ideais higienistas que visavam modernizar a cidade, realçando aquilo que nela remetia às paisagens urbanas europeias, ao passo que buscava extirpar da maneira mais violenta as habitações dos trabalhadores negros e mestiços. Em geral, pode-se dizer que o planejamento urbano no Recife neste período foi extremamente generoso em relação aos interesses da burguesia e perverso para com os trabalhadores.

Na verdade, o Estado vem contribuindo sistematicamente com os interesses da burguesia urbana, com a qual muitas vezes se confunde. E isso é facilmente perceptível dado o desvirtuamento e perversão da prática do planejamento urbano no transcurso de sua própria trajetória na cidade do Recife durante o século XX e início do século XXI. Tomemos como exemplo os planos físico-territoriais - desde os grandes planos de remodelação dos bairros centrais das décadas de 1920, 30 e 40 até os planos urbanos estratégicos de pequena escala do período atual. Percebe-se, em todos os momentos, a constante busca pela modernização da cidade atrelada ao crescimento econômico - em outras palavras, a 
busca pela valorização capitalista do espaço orientada segundo uma lógica vertical. Nem mesmo os planos regionais mais humanistas das décadas de 1950/60, formulados quando da introdução das ideias do Movimento Economia e Humanismo, ou mesmo os estudos e planos de larga escala das décadas de 1970/80, construídos pelas instituições municipais e estaduais de planejamento, fugiram da supracitada tendência. Em que pese as especificidades de cada época, tem sido essa, em geral, a principal regra para o planejamento da cidade: a valorização do espaço nos marcos do desenvolvimento capitalista.

Mesmo no âmbito das leis e do ordenamento territorial, em que foram constituídos marcos e diretrizes mais progressistas ao planejamento urbano e à gestão dos recursos municipais, a referida tendência não foi efetivamente questionada. Neste sentido, vale dizer que a Lei de Uso e Ocupação do Solo da Cidade do Recife (Lei n ${ }^{0}$ 14.511/83) com suas Zonas Especiais de Interesse Social (ZEIS), o Programa de Regularização das Zonas Especiais e Interesse Social (PREZEIS), o Orçamento Participativo e todo o conjunto de instrumentos jurídico-políticos para o zoneamento e gestão participativa instituídos pelo Estatuto da Cidade (Lei Federal $\mathrm{N}^{\mathrm{o}}$ 10.257/01) tem caminhado lado a lado com processos fragmentadores de valorização capitalista do espaço, muitos dos quais conduzidos pelo capital imobiliário.

Em outras palavras, mesmo quando na contravia de sua tendência precípua, nas poucas situações em que procurou fazer frente aos processos de fragmentação, o Estado não trouxe mudanças substanciais na forma por meio da qual o espaço urbano foi e tem sido (re)produzido. As supracitadas experiências não desencadearam grandes transformações porque não foram e ainda não são capazes de combater de maneira categórica aos processos mais recentes de (des-re)valorização capitalista e, pelo contrário, caminham junto ou, muitas vezes, contribuem com eles - a exemplo da última revisão do Plano Diretor do Recife ${ }^{3}$.

Soma-se à essa permanência do modelo de desenvolvimento e fragmentação do espaço, os limites técnicos do planejamento na apreensão dos "espaços liminares” (Gomes, 2008), isto é, a dificuldade em

\footnotetext{
${ }^{3}$ Referimo-nos ao incentivo à construção de parcerias público-privadas e operações urbanas consorciadas nas chamadas Zonas de Ambiente Construído de Ocupação Controlada. Tais zonas, diga-se de passagem, correspondem a alguns bairros da região sul da cidade, dentre os quais se inclui Boa Viagem, Pina e Brasília Teimosa. Este último, em contraste com os dois primeiros, surgiu de um processo histórico de luta popular pela permanência no lugar. A referida revisão, portanto, põe em risco a luta dessa população.
} 
compreender e intervir em formas espaciais que expressam materialmente a coexistência de tempos. Essa coexistência, a propósito, há muito tornou o modelo funcional de cidade obsoleto. A reprodução do trabalho formal e informal no âmbito do espaço residencial é um exemplo neste sentido (Gomes, 2002). E, no entanto, insiste-se em uma compartimentação sintática em espaços residenciais, comerciais, eixos viários etc., privilegiando muito mais os objetos do que os conteúdos. O resultado prático de tudo isso não poderia ser pior: a escandalosa desigualdade e os gravíssimos problemas ambientais são seletivamente diagnosticados, na grande maioria dos casos mal administrados e, não raro, intensificados.

Por isso a fragmentação ganha nos dias de hoje novos contornos. Essa cidade apresenta atualmente um dos piores índices de Gini entre as cidades brasileiras $(0,68)$, segundo dados do Atlas de Desenvolvimento Humano do Brasil - PNUD 20104. Contraditoriamente, o mercado imobiliário é um dos mais dinâmicos do país. Recife tem hoje o quinto metro quadrado $\left(5^{\circ} \mathrm{m}^{2}\right)$ mais caro do Brasil ${ }^{5}$ e uma considerável rede de serviços de luxo e shopping centers. Não obstante, a fragmentação também revela suas marcas por meio dos principais problemas socioambientais. Apenas para se ter uma ideia, segundo estimativas da Empresa de Limpeza Urbana do Recife (Emlurb), dos $54 \mathrm{~km}^{2}$ de áreas planas da cidade, 37 $\mathrm{km}^{2}$ estão sujeitas a alagamentos. O Recife ainda possui cerca de 3.400 pontos de risco de desabamento em morros e, segundo estimativas da Companhia Pernambucana de Saneamento (Compesa), apenas 35\% do território municipal é efetivamente saneado ${ }^{6}$.

Há ainda o padrão emblemático de fragmentação ocasionado pela irrupção dos "enclaves fortificados" (Caldeira, 2000), eufemisticamente chamados de condomínios, que hoje se difundem enquanto padrão residencial das mais diversas classes sociais, e cuja maior conseqüência tem sido a criação de uma "nova" ordem privada frente à implosão da vida pública. Trata-se, aliás, de uma atualidade recorrente nos países periféricos e produto da sociabilidade hegemônica em tempos de globalização. Essa

\footnotetext{
${ }^{4}$ Informação sobre índice de Gini no Recife foi retirada do portal Atlasbrasil.org.br, disponível em: http://www.atlasbrasil.org. br/2013/pt/perfil_m/recife_pe\#idh. Acesso em: 20 abr. 2015.

${ }^{5}$ Informação sobre preço médio dos imóveis com base nos índices FipeZap foi extraída do portal Exame.abril.com.br, disponível em: http://exame.abril.com.br//seu-dinheiro/noticias/as-cidades-com-imoveis-mais-caros-e-mais-baratosde-2014/lista. Acesso em 19 set. 2015.

${ }^{6}$ Informações sobre os problemas de infraestrutura no Recife foram extraídas de matéria especial do portal ne10.com, disponível em: http://especiais.ne10.uol.com.br/agenda_recife/index.html. Acesso em: 24 nov. 2014.
} 
"lógica do condomínio" (Dunker, 2015), pressupõe a exclusão daquilo (ou melhor, daqueles) que está fora dos muros, ao passo que conjectura uma ordem longe de imprevistos, dos encontros espontâneos entre os diferentes, conforme os padrões internacionais de consumo guarnecido. Em outras palavras, trata-se da opção pela ordem distante, da regulação hierárquica, em detrimento da ordem próxima, calcada na solidariedade horizontal, dos valores do lugar e da memória coletiva.

Essa mesma lógica hoje se estende ao planejamento e gestão das cidades, orientando e definindo os planos de desenvolvimento e os subjacentes processos de valorização do espaço. Na última década, por exemplo, investimentos realizados no contexto de parcerias públicas, como as obras do complexo viário Via Mangue ${ }^{7}$ e o surgimento de megaempreendimentos imobiliários, muito dos quais voltados para o turismo, para grandes eventos esportivose para o consumo de luxo, tem respaldado esse processo de “condominização”. É o caso das obras da Copa 2014, bem como do Shopping Riomar, do Projeto Novo Porto, do Condomínio Le Parc, da Reserva do Paiva e do Projeto Novo Recife. Envoltos em irregularidades jurídicas e conflitos sociais, esses projetos representam alguns dos desdobramentos mais recentes da fragmentação do espaço urbano em Recife.

\section{Projeto Novo Recife}

Essa fragmentação ganha novas dimensões no Recife a partir da década de 1990, quando da introdução formal do ideário do "empreendedorismo" na gestão da cidade. O empreendedorismo urbano, como bem observou David Harvey (2006b), diz respeito a um conjunto de tendências no planejamento urbano que se traduz na busca pela inserção de toda a cidade na lógica de acumulação do capital por meio de uma gestão empresarial de seu espaço, em que as ações se orientam com vistas à concorrência interurbana por ganhos econômicos. Tais ideias, inicialmente surgidas nas cidades europeias e norte-americanas, sempre estiveram presentes nos planos urbanos criados para a cidade do Recife, mas foram explicitamente assumidas na década de 1990, fazendo

\footnotetext{
${ }^{7}$ Via expressa para carros localizada entre os bairros de Boa Viagem e Pina, cuja extensão é de aproximadamente 4,5 km e cuja construção se deu por uma conflituosa ocupação do entorno de uma importante Área de Proteção Ambiental da cidade, o Parque dos Manguezais.
} 
com que o planejamento urbano voltasse sem reservas ao modelo de desenvolvimento aqui problematizado. É daí que surge, entre outras coisas, o Projeto Capital em 1999, plano estratégico inspirado em experiências internacionais e que visava a inserção do Recife nos fluxos econômicos globais.

O Projeto Capital reunia um conjunto de estratégias para o setor imobiliário, entre elas uma série de operações para os bairros centrais e ao sul da orla oceânica, de forma a integrar diferentes territórios da cidade aos fluxos econômicos globais (Bitoun, 2001). Para tanto, foram realizados diversos seminários com a presença de intelectuais e técnicos locais, além de urbanistas estrangeiros, muitos dos quais com trajetórias profissionais fortemente ligadas ao modelo de "planejamento estratégico". Na ocasião, também foi criado o "Fórum Capital", responsável pelos debates e estudos a respeitos dos planos de intervenção. O referido projeto não chegou a ser efetivamente implantado, mas um dos seus territórios foi objeto de lei para posterior construção de plano urbanístico, a Área Temporária de Reurbanização do Cais José Estelita, criada pela Lei municipal ${ }^{\circ}$ 16.550/2000 (Nunes, 2013).

As propostas do Projeto Capital foram retomadas, em 2006, pelo Projeto “Complexo turístico-cultural Recife/Olinda”, versão aparentemente mais democrática do plano anterior. Este segundo plano apontava diversas localidades da cidade que deveriam receber investimentos públicos e privados voltados para o turismo. Dentre tais localidades listavam toda a região da orla oceânica, a Bacia do Pina e o Cais José Estelita. Mais tarde, o abandono deste segundo projeto por parte do poder público deixou sem planos uma grande quantidade de terrenos públicos e privados, tornando-os disponíveis para as investidas do capital imobiliário que, desde o final dos anos 2000, estava conhecendo um vertiginoso crescimento. A aquisição do antigo terreno da Rede Ferroviária Federal S.A. - RFFSA, no Cais José Estelita, por parte de um consórcio de empresas, ilustra muito bem isso. Embora seguindo muitas das diretrizes prenunciadas pelo Estado por meio dos planos anteriores, o capital imobiliário passou a dispor de mais liberdade para propor um processo de valorização do espaço sem qualquer controle social. É assim que surge, então, o Projeto Novo Recife, a nova denominação dos projetos supracitados.

O Novo Recife é um empreendimento imobiliário de caráter particular, proposto por um consórcio de quatro empresas do ramo: Moura 
Dubeux, Queiroz Galvão, Ara Empreendimentos e GL Empreendimentos. Ele está prestes a ser implantado em uma localidade mercadologicamente valiosa da cidade, no Cais José Estelita, localizado entre os bairros do Cabanga e de São José, e próximo ao Forte das Cinco Pontas (Figura 1). O local e seu entorno possuem muitos sobrados e edifícios de pequeno porte, casarios antigos e vários bens tombados pelas instituições de memória, tais como a Igreja de São José e o próprio Forte das Cinco Pontas.

Figura 1: Imagem aérea do Cais José Estelita

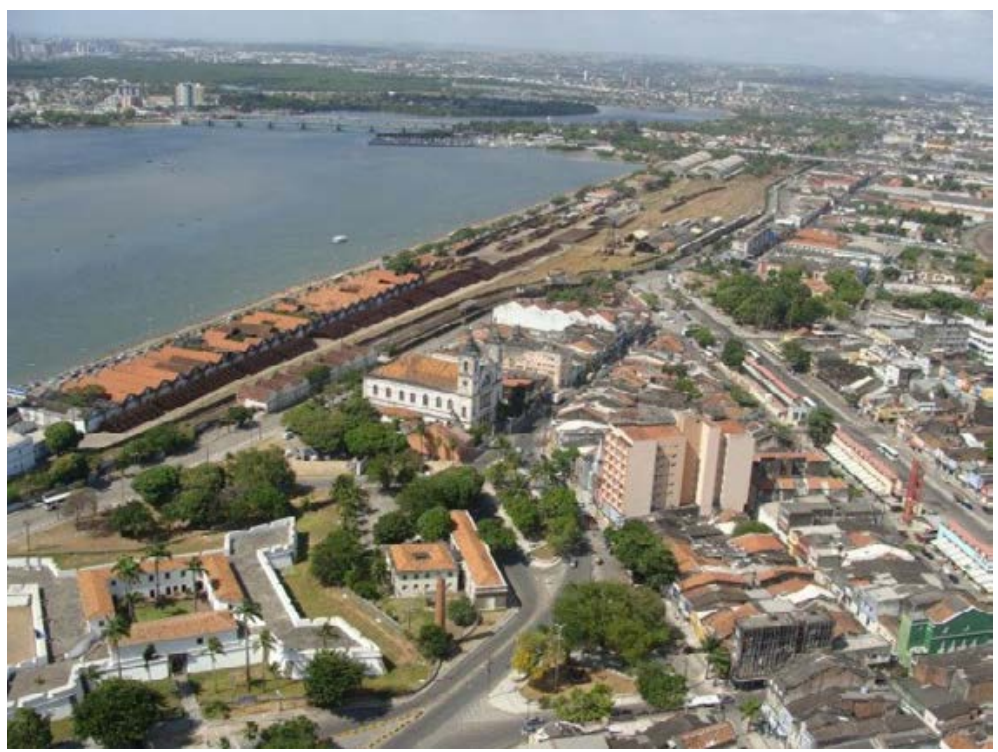

Fotografia extraída da página do grupo Direitos Urbanos

Disponível em: https://direitosurbanos.wordpress.com/2012/04/18/novo-recife-velha-mentalidade/

Acesso em: 15 fev. 2015

A área destinada ao projeto possui cerca de cem mil metros quadrados $\left(100.000 \mathrm{~m}^{2}\right)$ e está situada às margens da Bacia do Pina. Como dito, o terreno da RFFSA, patrimônio da União, foi adquirido pelo consórcio por meio de leilão que atualmente é objeto de investigação por parte da Polícia Federal. Tendo a proposta de revitalização, as empresas propõem inicialmente a construção de treze (13) edifícios, que variam entre vinte (20) e quarenta (40) andares, destinados ao funcionamento de redes hoteleiras, escritórios e habitações de luxo (Figura 2). 
Figura 2 - Imagem virtual do Projeto Novo Recife

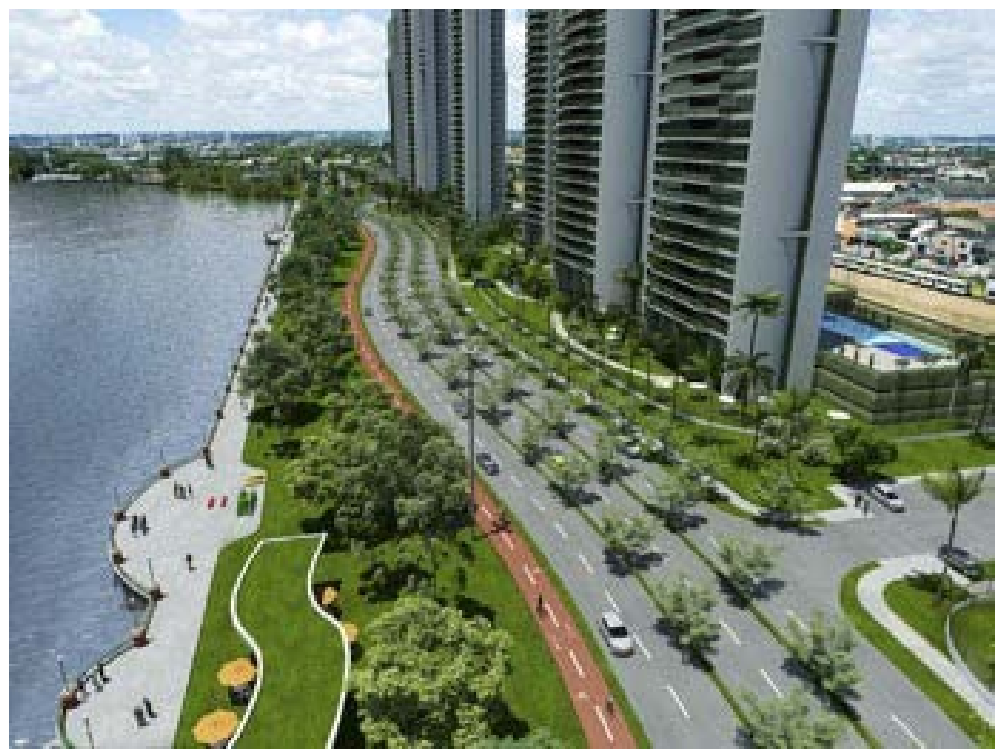

Fonte: G1.globo.com; Disponível em: http://g1.globo.com/pernambuco/noticia/2013/12/projeto-

novo-recife-e-aprovado-com-valor-dobrado-de-mitigacoes.html. Acesso em: 07 nov. 2014

O projeto ainda se articula com outros empreendimentos de luxo, como o Shopping Riomar, os edifícios de alto padrão dos bairros do Pina e de Boa Viagem, bem como o edifício empresarial do grupo JCPM. O complexo viário Via Mangue, por sua vez, é o responsável pela articulação dos referidos empreendimentos com os bairros do Pina e Boa Viagem. Trata-se de uma via pública feita especificamente para o trânsito de carros, construída no entorno da área de preservação ambiental Parque dos Manguezais, sendo essencial para o sucesso do Projeto Novo Recife em termos de acessibilidade.

O caráter privatista e segregador do projeto Novo Recife, junto à forma escusa por meio da qual ele foi aprovado pelas instâncias governamentais, gerou polêmicas e mobilização de estudantes e trabalhadores, que passaram a questionar a validade jurídica e a pertinência social e ambiental do projeto. Foi, inclusive, nesse contexto de questionamentos que insurgiu o grupo "Direitos Urbanos", fórum de debates aberto e não institucionalizado sobre a cidade para onde convergiram intelectuais, estudantes e trabalhadores contrários ao projeto. 
Membros desse grupo, junto ao Ministério Público e outras organizações sociais foram os responsáveis em desencadear o debate público sobre o projeto, movendo ações judiciais que questionam alguns de seus aspectos, desde o repasse do terreno por parte da União até a ausência de estudos obrigatórios, como os de Impacto Ambiental e de Vizinhança (Figura 03).

Figura 3 - Manifestação do "Ocupe Estelita”

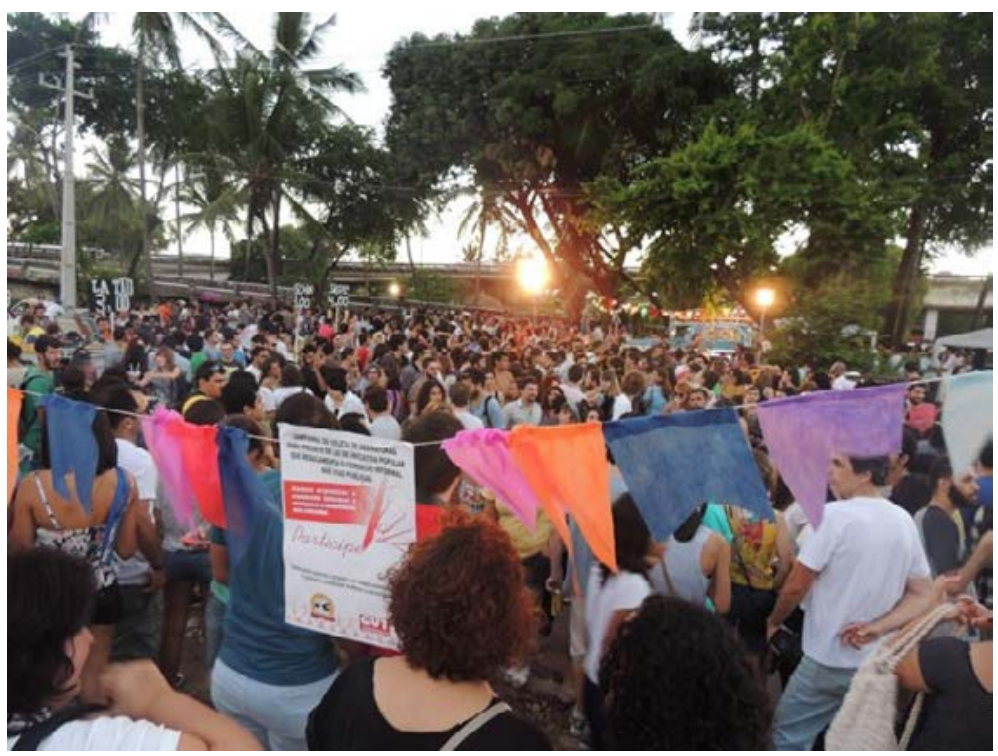

Fotografia: Vítor Tavares/G1, 2014; Disponível em: http://g1.globo.com/pernambuco/noticia/2014/06/recifetem-protesto-cultural-contra-plano-imobiliario-no-cais-jose-estelita.html. Acesso em: 07 nov. 2014

A pressão popular exercida por grupos contrários ao Novo Recife, pela via institucional e da "ocupação", forçou o poder público a realizar alguns ajustes no projeto, como a ampliação das chamadas "ações mitigadoras". Neste sentido, foram incluídos à proposta um parque, além de equipamentos públicos como quadras poliesportivas, áreas de lazer, biblioteca, ciclovias e a demolição do viaduto que existe hoje sobre o Forte das Cinco Pontas. Contudo, estima-se que os impactos socioambientais negativos superam e muito as ações mitigadoras ou quaisquer benefícios decorrentes da implantação do projeto, pois além de conservar o caráter privatista e segregador, o estilo arquitetônico dos edifícios previstos destoa enormemente daquele predominante nos bairros históricos 
circunvizinhos. Trata-se, dessa forma, de um processo perverso de (des-re) valorização capitalista, indutor de mais segregação e que, por certo, tornará o espaço da cidade ainda mais fragmentado.

Os aspectos negativos, então divulgados por diversos grupos sociais na sua luta contra o projeto, estão sendo objeto de pesquisas e estudos mais aprofundados ${ }^{8}$. Todavia, pode-se resumi-los nos seguintes itens:

i. Vetor de fragmentação do espaço: o projeto prevê a revalorização de um importante espaço da cidade, propondo a construção de formas espaciais que em tudo destoam de seu entorno, tendo em vista que o terreno se situa entre bairros históricos e centrais da cidade, próximo também do "Coque", bairro popular que possui uma representativa história de luta pela permanência na cidade. O espaço revalorizado provavelmente não se integrará a esse entorno, intensificando a fragmentação e criando mais um enclave fortificado exclusivo para a burguesia urbana. Também é previsto um aumento do custo de vida que poderá inviabilizar o consumo do espaço para algumas classes e, no limite, desencadear um processo de gentrificação.

ii. Descaracterização do lugar e desmonte da memória: a lógica destrutiva-construtiva dessa des-re-valorização, com suas modernas torres de trinta pavimentos, comprometerá a paisagem, pois minguará o descortino da paisagem (postal) do sítio arquitetônico dos bairros do Recife, São José e Santo Antônio (Veras, 2014). Os edifícios previstos no projeto constituirão, portanto, formas geográficas seriamente capazes de arruinar a memória da cidade, ofuscando aquelas que remetem a tempos e técnicas anteriores. Essa descaracterização do lugar, inclusive, tem sido um dos principais aspectos contra os quais se tem lutado, constituindo o mote por meio do qual grupos sociais como o Direitos Urbanos (como devido apoio

\footnotetext{
${ }^{8} 0$ frescor da mobilização contra o projeto faz com que ainda não se disponha de estudos mais detalhados sobre seus reais impactos, exceto algumas teses e dissertações defendidas, sobretudo, no Programa de Pós-graduação em Desenvolvimento Urbano da Universidade Federal de Pernambuco. Como os estudos obrigatórios de impacto ambiental e de vizinhança não foram realizados da maneira devida, ainda há poucos dados científicos que possam subsidiar os argumentos contra o Novo Recife. Entretanto, há evidências históricas e empíricas, há relatos de pessoas e comunidades inteiras que estão sendo impactadas. Há também um esforço científico recente para suprir essa necessidade de dados, conduzidos por estudantes, e grupos de pesquisas ligados à Universidade. Para mais informações e dados a respeito de toda a luta contra o projeto, os autores recomendam a visita à página eletrônica do grupo Direitos Urbanos: https://direitosurbanos.wordpress.com/
} 
do Ministério Público Federal e do Ministério da Cultura) tem impetrado junto aos institutos de memória o processo de tombamento do Pátio ferroviário das Cinco Pontas e de todo o Cais José Estelita.

iii. Impactos físico-ambientais nos ecossistemas locais: o projeto será construído na linha de costa, muito próximo ao estuário da Bacia do Pina. O ambiente é vulnerável, mas proporcionalmente importante para a fauna e flora local, sendo berço de inúmeras espécies animais. A valorização gerada pelo empreendimento poderá desencadear a sobrecarga desse ambiente no que concerne ao despejo de efluentes e poluição do ar, alterando negativamente não apenas a vida de espécies animais e vegetais, mas também dos trabalhadores da pesca que garantem seu sustento na região. Além disso, as torres podem funcionar como barreira artificial para a brisa advinda do oceano, ocasionando o aumento da temperatura dos demais bairros localizados a oeste.

Neste sentido, o desenvolvimento que se almeja com projeto é aquele que vimos problematizando. O "novo" pretendido pelo Projeto Novo Recife não corresponde, substancialmente, a novidade alguma. Pelo contrário, este projeto, por certo, reafirmará os processos já existentes de fragmentação do espaço, posto que se baseia em uma (des-re)valorização orientada segundo interesses estranhos ao lugar e que visa produzir, a despeitos das ações mitigatórias, um enclave de exclusividades destinado à burguesia urbana, relegando aos trabalhadores os subprodutos negativos de sua implantação e operação.

Cabe registrar que todos os debates desencadeados em função da aprovação e implantação do projeto Novo Recife surgiram por conta dos seus impactos evidentes. Entretanto, as empresas envolvidas possuem interesses comuns e compõem grupos empresariais que atuam em diversos ramos, inclusive o da comunicação. Por isso, os canais de TV e rádio, assim como os principais jornais impressos da região têm se empenhado na divulgação do que consideram benefícios do projeto, tais como a geração de emprego e renda. Assim, o projeto tem sido sugerido sob a áurea de um inquestionável desenvolvimento que, supõe-se, trará benefícios para todos. Quando, na verdade, diz respeito ao desenvolvimento capitalista, indutor de um processo de fragmentação do espaço que beneficia apenas a burguesia urbana. 
A força de tais empresas em impor suas estratégias provém, antes de tudo, de processos homogeneizantes que incidem sobre os lugares, fazendo-os adequar-se aos ditames do regime de capital. Porém tais empresas encontram no Estado o apoio necessário para fazer valer seus interesses. Neste sentido, cabe registra que as atuais administrações públicas locais têm sido complacentes com as irregularidades e impactos do projeto, negligenciando a conformidade com aspectos legais e esforçando-se em deslegitimar toda força política que tem erigido contra os interesses do consórcio.

O fato de que tais empresas financiaram as campanhas eleitorais do atual prefeito e do governador do Estado, bem como de muitos vereadores e deputados estaduais, evidenciam que o Novo Recife é muito mais que um simples projeto urbanístico, mas uma coalizão de interesses escusos, envolvendo o Capital e o Estado, cujo principal objetivo é realizar a tendência histórica do capitalismo de acumulação pela via do desenvolvimento e da (des-re)valorização do espaço. No caso, o espaço que se pretende produzir corresponde a uma vitrine para o consumo de luxo e para o turismo, que não tem qualquer relação com os reais interesses dos trabalhadores da cidade e que, ainda, contribuirá para a irrupção de problemas sociais e ambientais.

\section{Considerações Finais}

A referida cumplicidade e contribuição dos governantes em relação a tais empreendimentos apenas reiteram a ideia de que o Estado, em atenção aos interesses da burguesia urbana, vem contribuindo sistematicamente com o modelo de desenvolvimento capitalista e com seu consequente processo de fragmentação do espaço urbano. Tal cooperação é particularmente perceptível diante do desvirtuamento e da perversão da prática do planejamento urbano, cujas primeiras expressões, como vimos, remontam o início do século XX. Hoje, entretanto, há um verdadeiro vazio em termos de propostas para a cidade e uma postura de total subserviência dos gestores urbanos frente aos interesses do Capital. Situação essa que forçosamente nos leva a indagar se há, de fato, planejamento em Recife.

A gestão da cidade tem sido quase que inteiramente depositada nas mãos da iniciativa privada, inclusive o provimento e manutenção de infraestrutura básica, fazendo com que a cidade seja frequentemente 
acometida por obras pontuais e de pequena escala (vias, túneis, viadutos, edificações etc.), quase sempre surgidas de maneira desconexas e sob a inquestionável áurea do desenvolvimento, mas que são divulgadas ulteriormente como se já fizessem parte de uma estratégia anterior, devidamente respaldada pelo Estado.

O que os gestores vêm chamando de planejamento, portanto, corresponde a essa prática insignificante de apenas juntar os fragmentos, estabelecer eventuais conexões e sugerir, com base no aforismo do desenvolvimento, uma improvável e absurda pertinência social, ambiental e histórica de tais obras. Na verdade, segundo Albuquerque e Gomes (2013), tais obras constituem os "vetores do atual processo de reprodução do espaço urbano" no Recife e, dada a superficialidade e completa submissão ao capital, não possuem qualquer correspondência com algum modelo de planejamento, nem mesmo aqueles mais neoliberais, cuja a atuação do Estado deve ser mínima.

Em síntese, são esses os desdobramentos recentes da fragmentação do espaço em Recife: a plena capacidade do regime de capital em, por meio do desenvolvimento, realizar a (des-re)valorização do espaço, num processo que, por sua própria natureza desigual e lógica estranha ao lugar, tende a beneficiar apenas o atores hegemônicos do sistema-mundo. No caso do projeto Novo Recife, o que se constata é mais uma estratégia do capital no permanente processo de (des-re)valorização do espaço, cujos impactos sociais e ambientais mais uma vez recairão sobre os trabalhadores.

\section{Referências}

ALBUQUERQUE, M. Z; GOMES, E. T. A. Reflexões sobre vetores do atual processo de reprodução do espaço urbano no Recife. In: Simpósio Nacional de Geografia Urbana: ciência e ação política por uma abordagem crítica, 13, 2013, Rio de Janeiro. Anais (on-line). Rio de Janeiro: UERJ, 2013. p. 01-15. Disponível em: http://www.simpurb2013.com.br/wp-content/uploads/2013/11/GT09_ Mariana.pdf. Acesso em: 20 abr. 2015.

BITOUN, J. A contribuição dos planos estratégicos na gestão municipal: modernização do discurso, seletividade ou aprimoramento das práticas? In: SPOSITO, M. E (org.). Urbanização e cidades: perspectivas geográficas. Presidente Prudente: UNESP, 2001, p. 291-310.

CALDEIRA, T. P. R. Cidades de muros: crime, segregação e cidadania em São Paulo. São Paulo: Ed. 34, Edusp, 2000. 
CARLOS, A. F. A. A natureza do espaço fragmentado. In: SANTOS, M; SOUZA, M. A. A; SILVEIRA, M. L. Território globalização e fragmentação.4.ed. São Paulo: Ed. Hucitec, 1998. p. 191-197.

DAVIS, M. Planeta Favela. São Paulo: Boitempo, 2006.

DUNKER, C. I. L. Mal-estar, sofrimento e sintoma: uma psicopatologia do Brasil entre muros. São Paulo: Boitempo, 2015.

FALCÃO NETO, J. SOUZA, M. A. A. Mocambos do Recife: o direito de morar. Ciência Hoje, Recife, v. 3, n. 18, p. 74-80, 1985.

GOMES, E. T. A. Espaços liminares - conteúdos subvertem formas no processo contínuo de (re)produção da e na cidade contemporânea. Investigación y desarrollo, Barranquilla, v. 16, n. 1, p. 174-195, 2008.

. O trabalho desafiando o modelo funcional das cidades - entre a oficina como unidade produtiva e a casa como espaço reprodutor da força do trabalho. Scripta Nova, Barcelona, v. 6, n. 119 (78), 2002.

HARVEY, D. A produção capitalista do espaço. 2.ed. São Paulo: Annablume, 2006.

LEFEBVRE, H. O direito à cidade. 5.ed. São Paulo: Centauro, 2001.

MORAES, A. C. R; COSTA, W. M. Geografia crítica: a valorização do espaço. 2.ed. São Paulo: Hucitec, 1987.

NUNES, S. M. M. Da teoria à prática: um breve histórico do planejamento urbano no Recife, pós 1970. In: Encontro da Associação Nacional de Pós-graduação e Pesquisa em Planejamento Urbano e Regional: desenvolvimento, planejamento e governança, 15, 2013, Recife. Anais (on-line). Recife: UFPE, 2013. p. 01-16. Disponível em: http://unuhospedagem.com.br/revista/rbeur/index.php/anais/ article/view/4595/4464. Acesso em: 10 ago. 2015.

SALGUEIRO, T. B. Cidade pós-moderna: espaço fragmentado. Revista Território, v. 3, n. 4, p. 39-53, 1998.

SANTOS, M. Técnica, espaço, tempo: globalização e meio técnico-científico informacional. 2.ed. São Paulo: Hucitec, 1996.

. O espaço dividido: os dois circuitos da economia urbana dos países sub̄ $\bar{d}$ esenvolvidos. 2.ed. São Paulo: EDUSP, 2004.

- Por uma outra globalização: do pensamento único à consciência universal. 17.ed. Rio de Janeiro: Ed. Record, 2008.

SANTOS, M; SILVEIRA, M. L. O Brasil: território e sociedade no início do século XXI. 11.ed. Rio de Janeiro: Record, 2008.

VERAS, L. M. S. C. Paisagem-postal: a imagem e a palavra na compreensão de um Recife urbano. 2014. 467 f. Tese (Doutorado) - Universidade Federal de Pernambuco / Programa de Pós-graduação em Desenvolvimento Urbano, Recife, 2014. 
Otávio Augusto Alves dos Santos - Possui Graduação em Geografia pela Universidade Federal de Pernambuco. Mestrado em Desenvolvimento Urbano e Doutorando em Desenvolvimento Urbano pela mesma Universidade.

Edvânia Tôrres Aguiar Gomes - Graduada em Ciências Geográficas pela Universidade Católica de Pernambuco, Mestrado em Geografia pela Universidade Federal de Pernambuco e Doutorado em Geografia pela Universidade de São Paulo. Pós-doutorado na Universitat Leipzig (2009). Atualmente é professora Titular da Universidade Federal de Pernambuco.

Contribuição de cada autor no desenvolvimento do artigo:

Todos os autores ofereceram substanciais contribuições científicas e intelectuais ao estudo. As tarefas de concepção e design do estudo, preparação e redação do manuscrito foram realizadas pelo primeiro autor. $O$ segundo autor ficou especialmente responsável pelo desenvolvimento teórico-conceitual e revisão crítica.

Artigo recebido para publicação em 02 de abril de 2016 Aceito para publicação em 07 de maio de 2016 